\title{
Lung Tissue Distribution After Intravenous Administration of Grepafloxacin: Comparative Study With Levofloxacin
}

\author{
Hiroshi Yamamoto ${ }^{1}$, Tomonobu Koizumi ${ }^{1, *}$, Masao Hirota ${ }^{2}$, Toshimichi Kaneki ${ }^{1}$, Hitoshi Ogasawara ${ }^{1}$, \\ Yoshitaka Yamazaki ${ }^{1}$, Keisaku Fujimoto ${ }^{1}$ and Keishi Kubo ${ }^{1}$ \\ ${ }^{1}$ First Department of Internal Medicine, Shinshu University School of Medicine, 3-1-1 Asahi, Matsumoto 390-8621, Japan \\ ${ }^{2}$ Department of Drug Metabolism, Tokushima Research Institute, Otsuka Pharmaceutical Co., Ltd., \\ 463-10 Kagasuno Kawauchi-cho, Tokushima 771-0192, Japan
}

Received July 6, 2001 Accepted October 10, 2001

\begin{abstract}
The aim of the present study is to study the pharmacokinetics in plasma, lung lymph and bronchial washing fluid after intravenous infusion of grepafloxacin (GPFX), in comparison with those of levofloxacin (LVFX). Four conscious sheep with chronically instrumented lung lymph fistulas and tracheotomy were prepared. GPFX and LVFX concentrations in plasma and lung lymph after intravenous infusion of the drugs $(10 \mathrm{mg} / \mathrm{kg})$ for over $10 \mathrm{~min}$ were measured. In addition serial bronchial washing with $50 \mathrm{~mL}$ normal saline was performed to obtain epithelial lining fluid (ELF) at 2, 4, 6, 8, 12, $24 \mathrm{~h}$ after the intravenous administration. The time courses of lung lymph concentration were almost identical to those of the concomitant levels of both GPFX and LVFX in plasma, suggesting that both GPFX and LVFX could be easily moved from plasma to pulmonary interstitium and/or lung lymph circulation. However, GPFX concentrations of ELF were significantly higher than LVFX concentrations over time after the administration. In addition, intracellular concentrations in ELF of GPFX were also extremely high compared with those of LVFX. These results demonstrated that penetration of GPFX in bronchial wall, bronchial epithelium and/or phagocytic cells was superior to that of LVFX. These observations suggest that the pharmacokinetic characteristics of GPFX in the lung may provide a new insight into the strategy for clinical treatment of various pulmonary infections, especially cytotropic bacterial infections.
\end{abstract}

Keywords: Sheep, Epithelial lining fluid, Lung lymph fluid, New quinolone

New quinolones, which have been extensively developed in recent years, have potent, broad-spectrum antibacterial activity (1). Grepafloxacin (GPFX) and levofloxacin (LVFX) possess a wide spectrum of activity against both Gram-positive and Gram-negative bacteria $(2-4)$. However, while many pharmacokinetics studies of these agents have been done in patients and animals, little work has been reported on the behavior in the major target organ: lung and lung compartments. The pharmacokinetic behavior of antibacterials at the site of infection may be more relevant than that at circulating fluid. Furthermore, it has been noted that the frequency of intracellular infections with such respiratory pathogens as C. pnemoniae, Mycoplasma pneumoniae, L. pneumophila is increasing (5). There is a pharmacological interest to evaluate the antimicrobial delivery to infected cells $(6-8)$.

*Corresponding author. FAX: +81-263-36-3722

E-mail: tomonobu@hsp.md.shinshu-u.ac.jp
In the present study, we evaluated the pharmacokinetics of GPFX in the lung after the intravenous administration and compared them with those of LVFX. We studied the pharmacokinetics in plasma and lung lymph after its administration in order to investigate the movement and/or distribution of the drugs from the blood to lung lymph circulation and lung interstitium. Furthermore, we conducted serial bronchial washings after the administration and measured the concentrations in the fluid to investigate the movement and elimination of the drug in the epithelial lining fluid (ELF) and cell pellets. We used sheep as the experimental animal in this study, because the animal was large enough to provide samples easily and repeatedly.

\section{MATERIALS AND METHODS}

\section{Animal preparation}

Adult sheep weighting $32-38 \mathrm{~kg}$ were used. No animal had previously received any antibiotics and other drugs. 
This study was carried out in accordance with the Guidelines for Animal Experimentation of Shinshu University School of Medicine. We prepared conscious sheep with chronic lung lymph fistulas for the collection of lung lymph fluid, using the method of Staub et al. (9). Briefly, the sheep were anesthetized with intravenous pentobarbital sodium $(12.5 \mathrm{mg} / \mathrm{kg})$ and then ventilated with $0.5-1.0 \%$ halothane using positive pressure ventilation. Through a right thoracotomy in the sixth intercostal space, the efferent lymphatic channel from the caudal mediastinal node (CMN) was cannulated with a thin silicon tube. This tube was secured and brought to the outside. Through a second thoracotomy in the ninth intercostal space, the tail of the CMN was ligated at the free margin of the inferior pulmonary ligament to eliminate contamination with non-pulmonary lymph. We inserted catheters into the right carotid artery and extra jugular vein for the collection of blood and for drug infusion, respectively. The animals were then allowed to recover with free excess of food and water for at least 7 days before the experiment. The day before the experiment, thoracotomy was performed to facilitate bronchial washing.

\section{Experimental protocols}

GPFX and OPC-17203 (internal standard for GPFX and LVFX) were produced by Otsuka Pharmaceutical Company (Tokyo). We purchased commercial available tablets of LVFX and from these tablets, prepared the compound for this study. Chemical structures of GPFX and LVFX are shown in Fig. 1. All other regents and solvents were of special grade. Experiments were done with the animals awake and standing. Experiment 1: four sheep were administrated GPFX $(10 \mathrm{mg} / \mathrm{kg})$. Experiment 2: four sheep were administrated LVFX $(10 \mathrm{mg} / \mathrm{kg})$. These two agents were dissolved in $100 \mathrm{~mL}$ of normal saline and given to the animals by an intravenous infusion for $10 \mathrm{~min}$ via the extra jugular vein. Lung lymph was collected before infusion and at $10 \mathrm{~min}$ and $0.5,1,1.5,2,4,6,8$, 12 and $24 \mathrm{~h}$ after the start of the drug infusion. Blood samples were also drawn from aortic artery at the same time as lung lymph collections. Washing fluid from the lower respiratory tract was obtained by ELF through a

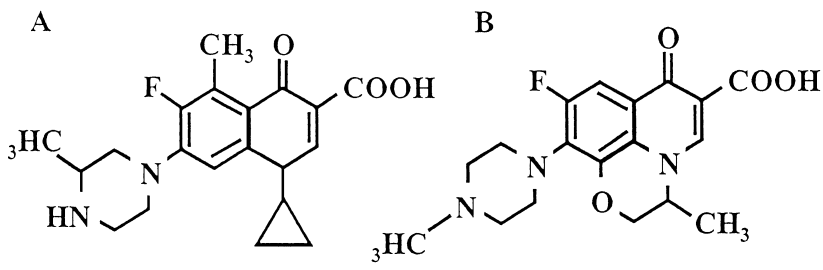

Fig. 1. Chemical structures of grepafloxacin (A) and levofloxacin (B). fiber-optic bronchoscope (length, $0.9 \mathrm{~mm}$; external diameter, $5.6 \mathrm{~mm}$; Olympus Co., Tokyo) using $50 \mathrm{~mL}$ normal saline. ELF was performed at 2, 4, 6, 8, 12 and $24 \mathrm{~h}$ after the drug infusion. Each ELF was done at a different site. Samples were centrifuged immediately at $4^{\circ} \mathrm{C}$, and the supernatants and pellet were frozen $\left(-80^{\circ} \mathrm{C}\right)$ until the time of analysis.

\section{Measurements of GPFX and LVFX concentrations}

GPFX and LVFX concentrations in the sheep were determined by high-performance liquid chromatography developed by Akiyama et al. (10) with modification. The method for measuring GPFX and LVFX concentrations in plasma, lung lymph, ELF supernatant and ELF pellet was as follows: $0.1 \mathrm{~mL}$ of $0.1 \mathrm{M}$ phosphate buffer ( $\mathrm{pH} 7.0$ ), $0.1 \mathrm{~mL}$ of $2 \mu \mathrm{g} / \mathrm{mL}$ OPC-17203 methanol solution and $1 \mathrm{~mL}$ of $25 \mathrm{mM} \mathrm{Na-K}$ phosphate buffer ( $\mathrm{pH}$ 6.86) were added to $0.1 \mathrm{~mL}$ of the sample. After mixing with a vortex mixer, the above mixtures were shaken with $5 \mathrm{~mL}$ of chloroform for $10 \mathrm{~min}$ for extraction. The residue was re-dissolved in $1 \mathrm{~mL}$ of mobile phase. Thirty microliters of the above re-dissolved mixture was injected into the HPLC system (Shimadzu, Kyoto). The analyses were performed with a TSK-gel ODS-80Ts column $(4.6 \mathrm{~mm} \times 150 \mathrm{~mm}$, Tosoh, Tokyo). The column temperature was $40^{\circ} \mathrm{C}$. The detection was monitored by fluorescence with excitation and emission set at 285 and $448 \mathrm{~nm}$, respectively. The mobile phase for quantification of GPFX and LVFX consisted of $\mathrm{CH}_{3} \mathrm{CN}: 20 \mathrm{mM} \mathrm{Na}_{2} \mathrm{SO}_{4}: \mathrm{H}_{3} \mathrm{PO}_{4}$ (1400:3600:4), and the flow rate was $0.8 \mathrm{~mL} / \mathrm{min}$. Protein content in ELF pellet was measured by DC protein assay kit (Bio-Rad, Hercules, CA, USA).

\section{Data and statistical analyses}

Data were expressed as means \pm S.D. of four independent experiments. The pharmacokinetic parameters, such as maximum concentration $\left(\mathrm{C}_{\max }\right)$ and the area under the concentration-time curve (AUC), were calculated by WinNonlin ver. 2.0 (Pharsight Corporation, Cary, NC, USA). We calculated the lymph to plasma concentration ratio $(\mathrm{L} / \mathrm{P})$ at each specified time after administration of GPFX and LVFX. The SAS system release 6.12 (SAS Institute Inc., Cary, NC, USA) was used to perform statistical analyses on the data. ANOVA on repeated measurements and the $t$-test were used as it allowed comparisons between GPLF and LVFX. Differences were considered to be statistically significant at $P<0.05$.

\section{RESULTS}

\section{Pharmacokinetics analysis in plasma and lung lymph}

Pharmacokinetic profiles of GPFX and LVFX in plasma and lung lymph after the infusion are summarized in Fig. 2 
and Table 1. The $\mathrm{C}_{0}$ of plasma GPFX was 7453.0 \pm $4372.5 \mathrm{ng} / \mathrm{mL}$, which was significantly lower than that of LVFX $(19181.4 \pm 7173.0 \mathrm{ng} / \mathrm{mL}, t$-test, $P<0.05)$. However, after that, the pattern and the values in plasma concen- trations of GPFX and LVFX were almost similar. The mean concentration in GPFX and LVFX decreased gradually to a level of $218.8 \pm 210.2,67.1 \pm 69.1 \mathrm{ng} / \mathrm{mL}$, respectively at $24 \mathrm{~h}$. The AUCs for both GPFX and LVFX were

\section{Plasma}

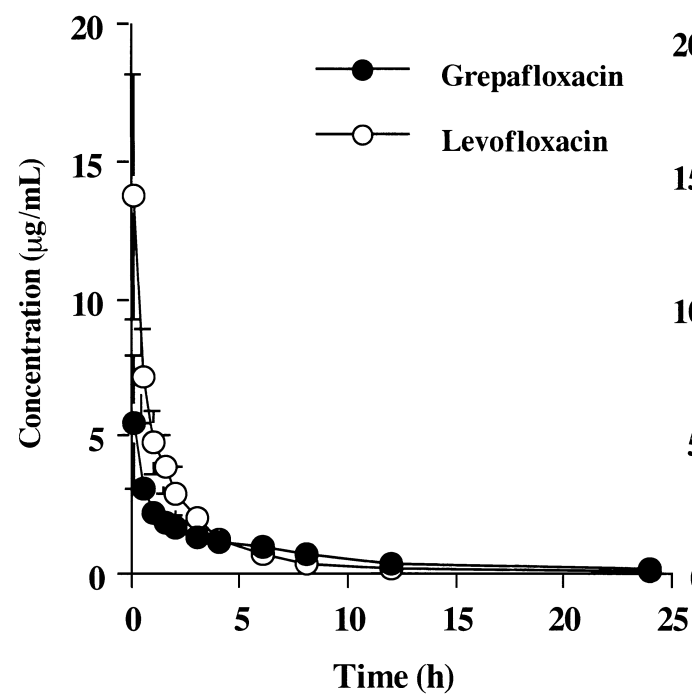

Lung Lymph

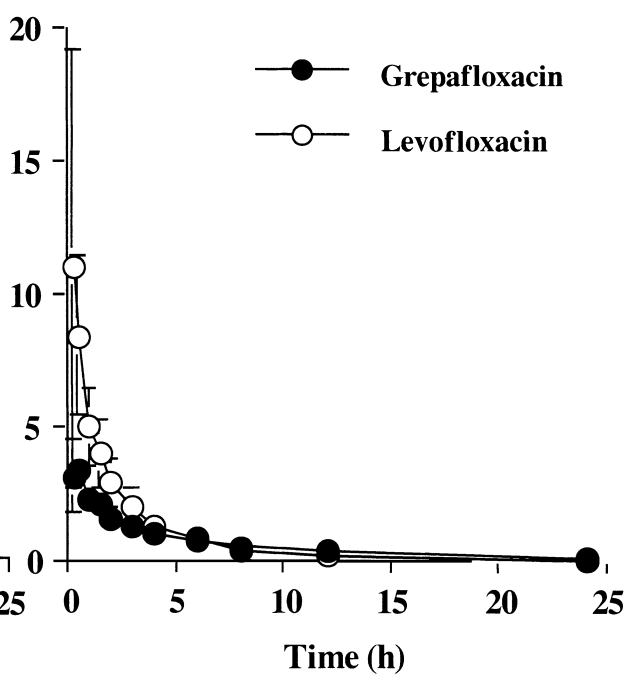

Fig. 2. Time course of mean concentrations of grepafloxacin and levofloxacin in plasma and lung lymph after drip administration in four sheep. The data are means with standard deviations.

Table 1. Pharmacokinetic parameters of grepafloxacin (GPFX) and levofloxacin (LVFX) after intravenous administration in four sheep

\begin{tabular}{|c|c|c|c|c|c|c|c|}
\hline \multirow[b]{2}{*}{ Matrix } & \multirow[b]{2}{*}{ Compound } & \multicolumn{6}{|c|}{$\mathrm{C}_{0}(\mathrm{ng} / \mathrm{mL})$} \\
\hline & & Animal-1 & Animal-2 & Animal-3 & Animal-4 & Average & S.D. \\
\hline \multirow[t]{2}{*}{ Plasma } & GPFX & 13878.0 & 6444.0 & 5187.1 & 4302.7 & $7453.0 *$ & 4372.5 \\
\hline & LVFX & 14241.3 & 20426.6 & 28825.4 & 13232.3 & 19181.4 & 7173.0 \\
\hline \multirow[t]{2}{*}{ Lung lymph } & GPFX & 4273.5 & 5924.0 & 3168.5 & 3722.2 & 4272.1 & 1190.1 \\
\hline & LVFX & 5912.4 & 7802.6 & 30538.5 & 12675.9 & 14232.4 & 11238.0 \\
\hline \multirow[t]{2}{*}{ ELF } & GPFX & 213.9 & 3480.1 & 893.8 & 195.1 & 1195.7 & 1557.2 \\
\hline & LVFX & 57.3 & 41.7 & 79.4 & 87.8 & 66.6 & 21.0 \\
\hline \multirow[t]{3}{*}{ Cell pellet } & GPFX & 860.7 & 1605.4 & 3835.5 & 1505.2 & 1951.7 & 1298.5 \\
\hline & LVFX & 50.3 & 92.9 & 84.8 & 360.7 & 147.2 & 143.5 \\
\hline & & \multicolumn{6}{|c|}{ AUC $(\mathrm{ng} \cdot \mathrm{h} / \mathrm{mL})$} \\
\hline Matrix & Compound & Animal-1 & Animal-2 & Animal-3 & Animal-4 & Average & S.D. \\
\hline \multirow[t]{2}{*}{ Plasma } & GPFX & 17204.8 & 21446.1 & 16478.4 & 34733.4 & 22465.7 & 8466.8 \\
\hline & LVFX & 14677.9 & 28608.6 & 28119.0 & 21112.3 & 23129.5 & 6593.3 \\
\hline \multirow[t]{2}{*}{ Lung lymph } & GPFX & 14046.1 & 19286.8 & 15242.1 & 16611.5 & 16296.6 & 2252.2 \\
\hline & LVFX & 11646.9 & 24403.0 & 32804.7 & 21690.6 & 22636.3 & 8721.2 \\
\hline \multirow[t]{2}{*}{ ELF } & GPFX & 2274.7 & 5765.6 & 3258.2 & 2188.5 & $3371.8^{*}$ & 1668.0 \\
\hline & LVFX & 274.7 & 289.3 & 797.4 & 276.8 & 409.6 & 258.6 \\
\hline \multirow[t]{2}{*}{ Cell pellet } & GPFX & 4165.1 & 11770.2 & 10968.3 & 8079.6 & 8745.8 & 3440.6 \\
\hline & LVFX & $\mathrm{a}$ & 12021.3 & 606.3 & 1700.0 & 4775.9 & 6298.5 \\
\hline
\end{tabular}

a: This value could not be calculated. *: $P<0.05$, between GPFX and LVFX. 
ELF

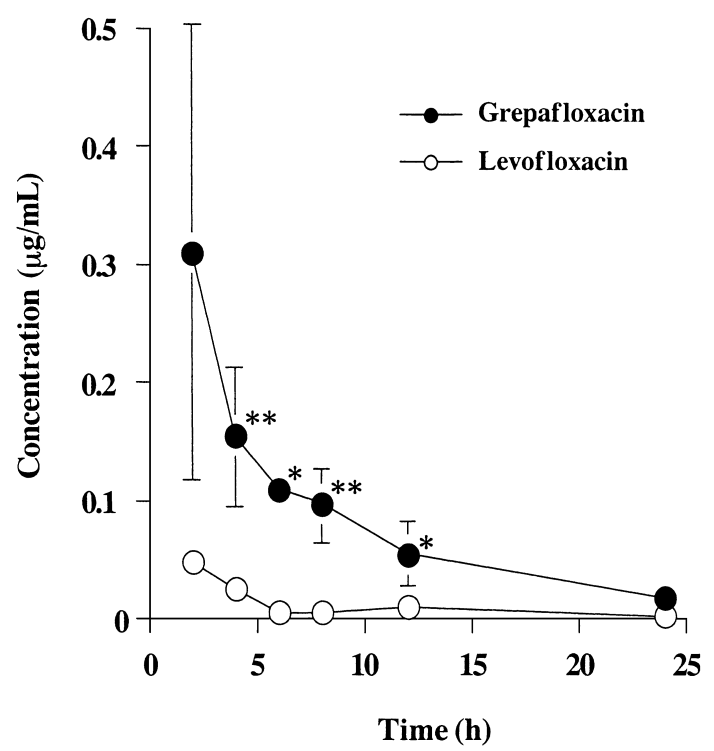

Cell pellet

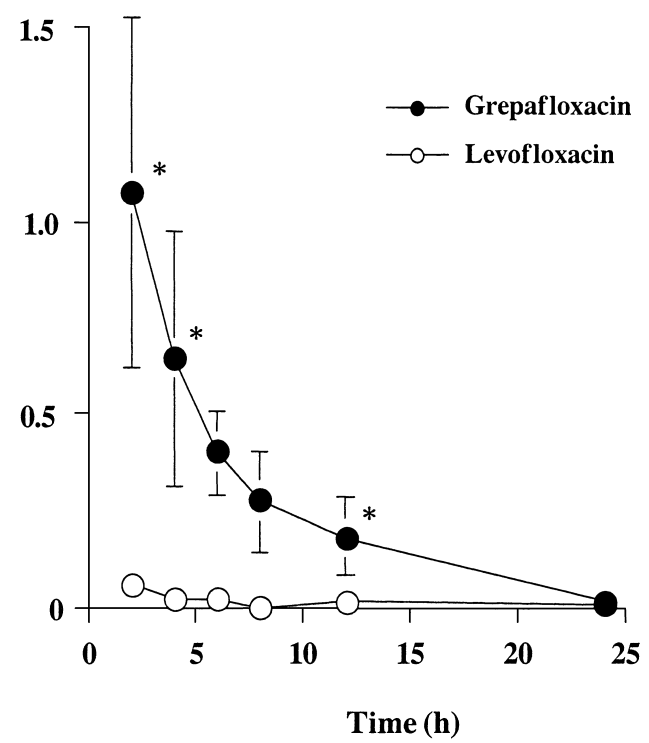

Fig. 3. Time course of mean concentrations of grepafloxacin and levofloxacin in epithelial lining fluid (ELF) and the cell pellets after drip administration in four sheep. The data are means with standard deviations. Significant difference from levofloxacin: $* P<0.05, * * P<0.01$.

identical. The time courses for lung lymph concentration were almost identical to the concomitant levels of plasma for both GPFX and LVFX. Thus, the concentration ratios of the lung lymph to plasma in GPFX and LVFX were almost 1.0, suggesting that both GPFX and LVFX could be easily moved from the plasma to pulmonary interstitium and/or lung lymph circulation.

\section{Pharmacokinetics analysis in ELF supernatant and pellet}

The time courses of mean GPFX and LVFX concentrations in ELF and the cell pellet are shown in Fig. 3 and Table 1. The recovery rate of ELF was $43.0 \pm 6.6 \%$ for GPFX and $41.8 \pm 5.2 \%$ for LVFX. These compounds were detectable in ELF supernatant at $2 \mathrm{~h}$ after the administration. Although the value of GPFX $(310.1 \pm 193.6 \mathrm{ng}$ $/ \mathrm{mL})$ was higher than LVFX $(46.4 \pm 3.8 \mathrm{ng} / \mathrm{mL})$, the difference was not significant. After that, mean GPFX concentrations in ELF supernatant were significantly higher than those of LVFX ( $t$-test; at $4 \mathrm{~h}, P<0.01$; at $6 \mathrm{~h}, P<0.05$; at $8 \mathrm{~h}, P<0.01$; at $12 \mathrm{~h}, P<0.05)$. Even after $12 \mathrm{~h}$ following administration, GPFX in ELF supernatant was detectable in all animals. The AUC in ELF concentration of GPFX was significantly higher than that of LVFX (Table 1).

In addition, GPFX concentrations in ELF pellet were extremely high compared to those of LVFX, suggesting a valid intracellular the penetration of GPFX. The concentration of GPFX in cell pellet at $2 \mathrm{~h}(1072.0 \pm 447.0 \mathrm{ng} / \mathrm{mL})$ was significantly higher than that of LVFX $(60.8 \pm 24.9 \mathrm{ng}$ $/ \mathrm{mL}, P<0.05)$. These results demonstrated that penetration of GPFX in bronchial wall, bronchial epithelium and/or phagocytic cells was superior to that of LVFX.

\section{DISCUSSION}

We evaluated the time courses of elimination for GPFX and LVFX in the plasma, lung lymph, ELF supernatant and ELF pellet following intravenous infusion. We found that the movement to the respiratory tract of GPFX was superior to that of LVFX, although $\mathrm{C}_{0}$ of GPFX in plasma was significantly lower than that of LVFX. GPFX is likely to offer an advantageous alternative over currently available therapies for bacterial respiratory infection.

Clinically, both GPFX and LVFX have been used orally. The oral absorption is rapid and essentially complete, plasma concentration versus time profiles following either oral or intravenous administration was almost similar in both GPFX (11) and LVFX $(12,13)$. Since the sheep is a ruminant animal, we speculate that pharmacokinetic profiles after intravenous administration have less intervariance than those after oral administration.

Since the lymph obtained from sheep has been confirmed to be of pulmonary origin, this model has been widely adopted for the studies of lung fluid and protein exchange (14). We think that pharmacokinetics in lung lymph circulation is a useful and encouraging method to evaluate the lung tissue distribution after the drug administration (15). Movements of the compounds to lung lymph depended on the molecular weight, affinity to protein binding and/or 
lipid solubility. It is well known that physicochemical characteristics of GPFX and LVFX are similar (16). There were no significant differences in the AUCs in lung lymph and in ratios of lymph to plasma concentration between GPFX and LVFX. Thus, the pharmacokinetic behaviors in pulmonary lymphatic channels are similar in both compounds.

However, we found large differences in the movement to the bronchial tree between GPFX and LVFX. We found that GPFX concentrations in ELF supernatant and pellet were extremely high compared to those of LVFX, indicating an excellent penetration of GPFX into the bronchial wall and/or phagocytic cells. Several investigators investigated the pharmacological behavior in the lungs after oral administration of GPFX. Based on the study by Cook et al. (17), following oral administration of $400 \mathrm{mg}$ of GPFX for 4 days in 24 healthy subjects, the mean concentration in bronchial mucosa was $3.60 \mathrm{mg} / \mathrm{kg}$, which surpassed the serum level $(1.23 \mathrm{mg} / \mathrm{L})$. They also found extremely high GPFX levels in ELF $(13.9 \mathrm{mg} / \mathrm{L})$ and alveolar macrophages $(209.0 \mathrm{mg} / \mathrm{L})$. On the contrary, LVFX showed a little lower penetration ratio of plasma to bronchial mucosa. Nakamori et al. (18) demonstrated that penetration ratios of plasma to bronchial mucosa were 1.15 and 1.59 after single doses of $100 \mathrm{mg}$ and $200 \mathrm{mg}$, respectively. Symonds et al. (19) demonstrated almost similar results, ranging from $0.65-1.18$ of bronchial mucosa to serum ratios in LVFX. In the present study, which was done by intravenous administration, obvious differences in the penetration of ELF were seen between GPFX and LVFX. Even in the other studies, GPFX concentrations in bronchial mucous significantly exceeded those achieved with ciprofloxacin (20) and temafloxacin (21). The GPFX concentration in the lung tissue in normal animals was $7-10$ times higher than that of serum level after intravenous administration $(22,23)$. Those elevated ratios of the lung tissue to serum of GPFX were significantly highest among those of other quinolones. Based on these studies including our data, GPFX showed good penetration into the bronchial wall and would appear to have an advantage as an agent for the treatment of respiratory tract infections.

The intracellular distribution of the drug is also important in the treatment of infection caused by the so-called cytozoic bacteria, such as Legionella pneumophila, Chlamydia pneumoniae, mycoplasma pneumoniae, et al. These species grow in the phagocytic cells. In the studies, which evaluated the penetration of various antimicrobial agents into human polymorphonuclear leukocytes, new quinolones have relative high intra/extracellular ratios of between 2 to 8 in drug concentrations $(6,16)$. LVFX also showed high intra/extracellular ratios of $9.8 \pm 0.9$ in neutrophils. However, GPFX demonstrated an extremely high ratio of greater than 60 . These values were still higher than that of clindamycin (7) or macrolides (8). We found that in the present study, GPFX concentrations of ELF pellet were higher than LVFX concentrations. This result suggests a higher intracellular uptake of GPFX. Although ELF pellets included several types of cells, such as macrophages, neutrophils and epithelial cells obtained by bronchial washing with $50 \mathrm{~mL}$ normal saline, the main cell population was macrophages (24). Likewise, several studies demonstrated that GPFX accumulation into the macrophages was high $(21,25)$. Thus, based on these studies including our data, it should be emphasized that GPFX had excellent cell affinity in the lung. The mechanism of the beneficial accumulation of GPFX in lung tissue is still unclear in the present study. The distribution to the cellular organelle, including that in lung, of several new quinolones is dependent on the lipid solubility (26). The partition coefficient of GPFX is higher than that of LVFX (26). In addition, Taira et al. (16) suggested that GPFX accumulation into neutrophils was related to an active transport mechanism. These factors of GPFX may contribute to the better transport process in the lung tissue than LVFX.

In summary, we have described the lung lymph distribution and penetration into the bronchial tree and/or phagocytic cells of GPFX and LVFX after intravenous administration. GPFX had high affinity for lung tissues, especially bronchial wall. When we evaluate pharmacokinetic characteristics of antibacterial agents, it is necessary to study the pharmacokinetic behavior at the inflammatory site.

\section{REFERENCES}

1 Grossman RF: The role of fluoroquinolones in respiratory tract infections. J Antimicrob Chemother 40, 59 - 62 (1997)

2 Landtry HD and Lamb HM: Levofloxacin. Its use in infections of the respiratory tract, skin, soft tissues and urinary tract. Drugs 56, 487 - 515 (1998)

3 O'Doherty B, Dutchman DA, Pettit R and Maroli A: Randomized, double-blind, comparative study of grepafloxacin and amoxycillin in the treatment of patients with communityacquired pneumonia. J Antimicrobiol Chemother 40, 73-81 (1997)

4 Moola S, Hagberg L, Churchyard GA, Dylewski JS, Sedani S and Staley H: A multicenter study of grepafloxacin and clarithromycin in the treatment of patients with communityacquired pneumonia. Chest 116, 974 - 983 (1999)

5 Meyer RD and Finch RG: Community acquired pneumonia. J Hospital Infection 22, 51 - 54 (1992)

6 Garraffo R, Jambou D, Chichmanian EM, Ravoire S and Lapalus P: In vitro and in vivo ciprofloxacin pharmacokinetics in human neutrophils. Antimicrob Agents Chemother 35, 2215 2218 (1991)

7 Klempner MS and Styrt B: Clindamycin uptake by human neutrophils. J Infect Dis 144, 472 - 479 (1981) 
8 Ishiguro M, Koga H, Kohno S, Hayashi T, Yamaguchi K and Hirota M: Penetration of macrolides into human polymorphonuclear leukocytes. J Antimicrob Chemother 24, 719 - 729 (1989)

9 Staub NC, Bland RD, Brigham KL, Demling R, Erdman AJ and Woolverton WC: Preparation of chronic lung lymph fistulas in sheep. J Surg Res 19, 315 - 320 (1975)

10 Akiyama H, Abe Y, Koike M, Kyuushiki K, Fujio N, Odomi M, Mukai $\mathrm{F}$ and Ohmori K: Pharmacokinetics of grepafloxacin (I) - absorption, distribution and excretion after oral administration of grepafloxacin in animals as determined by HPLC Jpn J Chemother 43, 99 - 106 (1995)

11 Child J, Andrews JM and Wise R: Pharmacokinetics and tissue penetration of the new fluoroquinolone grepafloxacin. Antimicrob Agents Chemother 39, 513 - 515 (1995)

12 Lee LJ, Sha X, Gotfried MH, Howard JR, Dix RK and Fish DN: Penetration of levofloxacin into lung tissue after oral administration to subjects undergoing lung biopsy or lobectomy. Pharmacotherapy 18, 35 - 41 (1998)

13 Fish DN and Chow AT: The clinical pharmacokinetics of levofloxacin. Drug Metab Dispos 32, 101 - 119 (1997)

14 Koizumi T, Roselli RJ, Parker RE, Hermo CI, Banerjee M and Newman JH: Clearance of filtered fluid from the lung during exercise: role of hyperpnea. Am J Respir Crit Care Med 163, $614-618$ (2001)

15 Koizuimi T, Kubo K, Shinozaki S, Koyama S, Amari T, Hayano T, Fujimoto K, Kobayashi T, Sekiguchi M, Sakai R, Ohshima T and Miyamoto K: Pharmacokinetic evaluation of (glycolato$O, O^{\prime}$ )diammine platinum(II) in lung lymph in sheep. Jpn $\mathrm{J}$ Cancer Res 84, 468 - 473 (1993)

16 Taira K, Koga H and Kohno S: Accumulation of a newly developed fluoroquinolone, OPC-17116, by human polymorphonuclear leukocytes. Antimicrob Agents Chemother 37, $1877-$ 1881 (1993)

17 Cook PJ, Andrews JM, Wise R, Honeybourne D and Moudgil $\mathrm{H}$ : Concentrations of OPC-17116, a new fluroquinolone antibacterial, in serum and lung compartments. J Antimicrob
Chemother 35, 317 - 326 (1995)

18 Nakamori Y, Tsuboi E and Narui K: Sputum penetration of levofloxacin and its clinical efficacy in patients with chronic lower respiratory tract infections. Jpn J Antibiot 45, 539-549 (1992) (text in Japanese with English abstract)

19 Symonds J, Javaid A, Bone M and Turner A: The penetration of ofloxacin into bronchial secretions. J Antimicrob Chemother 22, 91 - 95 (1988)

20 Honeybourne D, Andrews JM, Ashby JP, Lodwick R and Wise $\mathrm{R}$ : Evaluation of the penetration of ciprofloxacin and amoxicillin into the bronchial mucosa. Thorax 43, 715 - 719 (1988)

21 Baldwin DR, Wise R, Andrews JM, Ashby JP and Honeybourne D: The distribution of temafloxacin in bronchial epithelial lining fluid, alveolar macrophages and bronchial mucosa. Eur Respir J 5, 471 - 476 (1992)

22 Imada T, Miyazaki S, Nishida N, Yamaguchi K and Goto S: In vitro and in vivo antibacterial activities of a new quinolone, OPC-17116. Antimicob Agents Chemother 36, 573-579 (1992)

23 Nakajima Y, Hattori K, Shinsei M, Matsunaga N, Iizasa H, Sasabe H, Akiyama H, Miyamoto G and Nakajima E: Physiologically-based pharmacokinetic analysis of grepafloxacin. Biol Pharm Bull 23, 1077 - 1083 (2000)

24 Fujimoto K, Kubo K, Okada K, Kobayashi T, Sekiguchi M and Sakai A: Effect of the 21-aminosteriod U-74006F on antigen-induced bronchoconstriction and bronchoalveolar eosinophilla in allergic sheep. Eur Respir J 9, 2044 - 2049 (1996)

25 Hirota M, Totsu T, Adachi F, Kamikawa K, Watanabe J, Kanegasaki S and Nakata K: Comparison of antimucobacterial activity of grepafloxacin against Mycobacterium avium with that of levofloxacin: accumulation of grepafloxacin in human macrophages. J Infect Chemother 7, 16-21 (2001)

26 Murata M, Tamai I, Sai Y, Nagata O, Kato H and Tsuji A: Carrier-mediated lung distribution of HSR-903, a new quinolone antibacterial agent. J Pharmacol Exp Ther 289, 79 - 84 (1999) 